\title{
ABORDAGEM PSICOTERÁPICA DA CRIANÇA E DA FAMÍLIA NO HOSPITAL DAS CLÍNICAS DA FACULDADE DE MEDICINA DE RIBEIRÃO PRETO - USP
}

\author{
PSYCHOTHERAPEUTIC APPROACH TO CHILDREN AND FAMILY OF THE \\ UNIVERSITY OF SÃO PAULO - RIBEIRÃO PRETO GENERAL HOSPITAL
}

José H. Golfeto \& Heloísa Mian²

'Docente do Departamento de Neurologia, Psiquiatria e Psicologia Médica e ${ }^{2}$ Médica Psiquiatra Infantil Assistente do Hospital das Clínicas - Faculdade de Medicina de Ribeirão Preto da Universidade de São Paulo.

CorResPondência: Prof.Dr. José H. Golfeto - Av. Nove de Julho, 980 - CEP: 14025-000 - Ribeirão Preto - SP; Fone: (016) 625-0309

GOLFETO JH \& MIAN H. Abordagem psicoterápica da criança e da família no Hospital das Clínicas da Faculdade de Medicina de Ribeirão Preto - USP. Medicina, Ribeirão Preto, 32: 203-210, abr./jun. 1999.

RESUMO: A psicoterapia é um dos recursos utilizados na Psiquiatria Infantil, assim como a orientação familiar e a psicofarmacoterapia. Pode receber diferentes classificações de acordo com o fundamento teórico, alvo da intervenção e duração ou objetivo da terapia. Pretendemos fazer um relato da técnica psicoterápica, adotada no Ambulatório de Psiquiatria Infantil do Hospital das Clínicas da FMRP-USP, denominada de tempo limitado, assim como fazer um paralelo com técnicas utilizadas na psicoterapia longa. Relatamos, também, aspectos da orientação familiar por nós realizada. Os casos atendidos são previamente avaliados e, após discussão clínica, é feita a indicação dos procedimentos a serem adotados, que podem ser desenvolvidos isoladamente ou associados entre si.

UNITERMOS: Psiquiatria Infantil. Psicoterapia. Criança. Orientação. Família.

\section{INTRODUÇÃO}

A Psiquiatria Infantil, apesar de ser uma especialidade reconhecida recentemente, está inserida, desde a década de 70, no programa de formação de médicos residentes em Psiquiatria do Hospital das Clínicas da Faculdade de Medicina de Ribeirão Preto - USP (HCFMRP - USP), atuando como formação complementar, com duração de um ano, após cumpridos os dois anos de formação básica em Psiquiatria.

Oferece diferentes modalidades de atendimentos. No Pronto Atendimento de Psiquiatria Infantil, são realizadas as triagens e feitas as indicações que podem ser de tratamento psicofarmacológico, psicoterapia individual ou grupal e orientação familiar.
Pretendemos, com este trabalho, descrever a técnica psicoterápica e orientação familiar utilizadas pelos médicos residentes no atendimento de crianças no Hospital das Clínicas da Faculdade de Medicina de Ribeirão Preto - USP.

\section{PSICOTERAPIA}

Pode-se definir psicoterapia como o uso de recursos psicológicos para fins terapêuticos. É a utilização de certos processos, mobilizados na relação psicoterapeuta e paciente, com propósito de influenciar no sentido de ajuda, orientação ou modificação de atitudes e comportamentos patológicos ou simplesmente inadequados $^{(1)}$. 
As psicoterapias podem ser classificadas de diversas formas, de acordo com os fundamentos teóricos (psicodinâmica, comportamental e cognitiva), em relação ao alvo da intervenção (indivíduo, pais, família, grupo), e de acordo com a duração ou objetivos da terapia (intervenção na crise, apoio, remoção de sintoma, reconstrução da personalidade, etc) ${ }^{(2)}$.

A psicoterapia deve ter a função de fazer desaparecer o processo psicopatológico, minorar as dificuldades da personalidade, ou então, se existirem fatores orgânicos, de restaurar a linha normal do desenvolvimento e favorecer o processo de maturação, permitindo que, como força positiva, libere a tendência à auto-realização.

Elege-se e utiliza-se a técnica psicoterápica segundo os caracteres da personalidade, o quadro clínico e a finalidade a que se propõe a psicoterapia. Os recursos técnicos são numerosos e o seu arsenal é continuamente enriquecido; porém, só adquirem utilidade e sentido quando se define o propósito com que são usados e a finalidade a que se aspira a chegar com eles.

Levando-se em consideração as peculiaridades inerentes à clientela atendida, o grande volume de procura e o tempo limitado de um ano da permanência do médico residente no Ambulatório de Psiquiatria Infantil do Hospital das Clínicas da Faculdade de Medicina de Ribeirão Preto - USP, adotamos a psicoterapia de tempo limitado como modelo e objetivo para nossos atendimentos.

Pretendemos com este trabalho focalizar a técnica por nós aplicada, bem como fazer um paralelo com técnicas de abordagem longa, que utilizam métodos interpretativos. Salientamos que ela não é nem melhor e nem pior que a psicoterapia longa com "insight".

A psicoterapia de tempo limitado tem seus próprios fundamentos teóricos e práticos, dentre os quais se destaca o contrato terapêutico pelo qual se estabelecem o número de sessões e a época do término. No período estabelecido de tempo limitado, procura-se cumprir com os objetivos psicoterápicos. Ela é desenvolvida com a criança no decorrer de um ano, na frequiência de duas sessões semanais, com a duração de cinqüenta minutos cada.

Atuamos com crianças em diferentes psicopatologias, nos diversos tipos de crise e emergências, nos desajustes emocionais e nas síndromes orgânico-cerebrais, bem como nos conflitos familiares, relacionados à problemática da criança.
Nossa técnica é baseada em uma abordagem terapêutica não interpretativa e não transferencial e, quando necessário, associada ao psicofármaco, cuja finalidade é abreviar o processo terapêutico no sentido de tornar a criança assintomática. Esta técnica cabe mais à nossa realidade, porque toda psicoterapia tem que se basear no diagnóstico e este inclui não somente os mecanismos de defesa, as estruturas psicopatológicas do ego como também as condições sócio-econômicas e culturais do paciente. $\mathrm{O}$ fator tempo também é extremamente relevante no processo de escolha da terapia a ser aplicada na criança. O médico residente fica no ambulatório um ano e se adotássemos uma técnica interpretativa esta seria provavelmente menos eficaz. Ainda temos a considerar que o nosso paciente é, na maior parte das vezes, pertencente ao baixo nível sócio-econômico e cultural e para ele é mais indicada a psicoterapia de tempo limitado.

Esta terapia se baseia em não estimular a regressão, em permitir à criança uma elaboração mais cognitiva do que a terapia de "insight" ou profunda. Esta técnica ainda dá condições de auto-expressão à criança, bem como de libertação de seus sentimentos e dificuldades de relacionamentos interpessoais.

Acreditamos que há uma força poderosa dentro de cada indivíduo que luta continuamente para uma completa auto-realização. Esta força conduz o ser humano para maturidade, independência e autodireção. A criança, além disso, necessita de bom terreno para o desenvolvimento de uma estrutura de personalidade equilibrada. Ela necessita de liberdade para ser ela mesma ${ }^{(3)}$. Por outro lado, a função do terapeuta é de reconhecer, compreender, como também dar liberdade de expressão na situação lúdica, sem avaliação crítica ou pressão para a mudança.

O terapeuta deve reconhecer e esclarecer ao paciente suas atitudes emocionais expressas e oferecer-lhe a oportunidade de se conhecer. Isto exige por parte do terapeuta uma grande capacidade de empatia e uma forma de ser flexível e não crítica. Ele deve saber usar a inspiração, a percepção e a intuição junto à criança. É um tipo de comunicação que vai além da sugestão.

Durante o tempo que dura a terapia, estabelece-se entre o terapeuta e a criança uma relação que permite à mesma expressar seu autêntico modo de ser, em virtude da aceitação do terapeuta, o que a leva a ganhar autoconfiança ${ }^{(4)}$. 
A prática psicoterápica deve fundamentar-se em uma relação onde existe uma atmosfera de segurança, de modo que a criança possa se expressar livremente, sem inibição de seus sentimentos. $\mathrm{O}$ terapeuta reconhece os sentimentos que a mesma deseja expressar e devolve-os de forma que ela possa entender o próprio comportamento. Ele deve ainda criar oportunidades para que ela resolva seus problemas.

A criança vive seu próprio mundo e poucos são os adultos que realmente o compreende; por isso, às vezes, é difícil para a criança estabelecer com os adultos uma relação de confiança ${ }^{(5)}$. Sendo assim, a criança assinala o caminho da terapia e o terapeuta deve segui-lo sem cercear a liberdade de atuação dela, sem acelerar a marcha do tratamento, mas deve estabelecer os limites necessários para que ela assuma parte da responsabilidade na relação.

A relação que se cria entre o terapeuta e o paciente constitui um fator decisivo no tratamento. $\mathrm{O}$ terapeuta deve esforçar-se em compreendê-la, deve examinar constantemente suas próprias relações e aprender a julgar autocriticamente em que grau seu trabalho está de acordo com os princípios fundamentais descritos.

O terapeuta interessa-se especificamente pelos próprios processos de crescimento da criança e pela remoção dos bloqueios ao desenvolvimento que podem ter-se tornado evidentes.

É bom recordar que o brincar é por si mesmo uma terapia. Conseguir que as crianças possam brincar é em si mesmo uma psicoterapia que possui aplicação imediata e universal, e inclui o estabelecimento de uma atitude social positiva com respeito ao brincar. Esse brincar tem de ser espontâneo, e não submisso ou aquiescente, se é que se quer fazer psicoterapia ${ }^{(6)}$

A função do terapeuta é permitir que a criança brinque, exponha seus sentimentos acumulados de tensão, frustração, insegurança, agressividade e medo. É isso que torna eficaz o método, mas deve-se acrescentar a isso a personalidade do terapeuta, que atua em um tipo de intercomunicação que permite ao paciente se conscientizar de suas dificuldades, enfrentando-as e aprendendo a controlá-las ou até mesmo esquecê-las.

O terapeuta infantil deve saber improvisar, fantasiar com as crianças, amá-las e principalmente ser paciencioso. $\mathrm{O}$ amor, a tolerância e a paciência são fatores que curam. Deve permitir que ela ponha à prova suas idéias, expressando-se plenamente. As- sim, a criança sente que as ordens, sugestões, recriminações, restrições, críticas e desaprovações do adulto desaparecem. Ela pode brincar com os brinquedos da forma que gostar, expressando seus sentimentos de ódio, de amor e de agressividade, entre outros. É fundamental a presença de um terapeuta compreensivo, que a aceite e lhe dê sensação de segurança, permitindo que se sinta segura e dê vazão à sua liberdade interior, que é fortalecida pelo número ínfimo de vezes em que o mesmo impõe limitações necessárias. É desta maneira que ocorre, por parte da criança, a vivificação das forças afetivas que levam à fantasia, que é a mãe de todas as possibilidades, e que se produz durante a atividade lúdica ${ }^{(7)}$. Isto é de máxima importância para a saúde do ser humano e para a formação do seu ego. O terapeuta é, ao mesmo tempo, o espaço, a proteção e o limite ${ }^{(4)}$.

No Ambulatório de Psiquiatria Infantil do HCRP-USP, os médicos residentes atuam com pacientes em diferentes psicopatologias, nos diversos tipos de crises e emergências, nos desajustes emocionais e nas síndromes orgânico-cerebrais. Atuam, ainda, nos conflitos familiares, relacionados à problemática da criança. Procuram, assim, localizar o foco ou o principal centro de conflito na criança e no meio familiar. A modalidade psicoterápica não interpretativa talvez não seja a ideal, mas é o máximo que se pode fazer no período de um ano em que o residente em Psiquiatria Infantil permanece no ambulatório. Disto decorre a aplicação de uma psicoterapia não profunda, baseada na percepção intuitiva do terapeuta com maior ou menor captação das necessidades do paciente.

A psicoterapia longa baseia-se nos seguintes aspectos: estimulação de regressão; emergência da transferência e contra-transferência; "insight" e transformação dos objetos internos através da projeção, introjeção e outros mecanismos de defesa fundamentais e complexos; além da amplificação das representações simbólicas para amplificação da consciência. Neste tipo de psicoterapia, o importante é reviver com o terapeuta a história de vida real ou em fantasia ${ }^{(8)}$. Essa modalidade terapêutica é aplicada em nosso ambulatório pelos médicos assistentes e docente.

Ao se aplicar a psicoterapia de tempo limitado, é evitada o máximo possível a regressão, porque esta ativa conflitos profundos e para que se consiga reelaborá-los num processo terapêutico, exigir-se-ia maior treinamento do terapeuta residente e uma formação mais ampla nas técnicas terapêuticas de base psicodinâmica. 
O mesmo se pode dizer em relação ao segundo aspecto da psicoterapia longa, que é o da transferência, na qual o paciente revivencia os aspectos de sua vida passada na pessoa do terapeuta. Isto é evitado pelos mesmos motivos já expostos quanto à regressão, visto que esse processo terapêutico estimula também o reaparecimento da sintomatologia regressiva. A utilização da transferência deve ser muito mais para compreender o paciente do que um instrumento a serviço da regressão, pois, na psicoterapia de tempo limitado, não se dá a elaboração no sentido profundo de um conflito e, sim, mostra-se ao paciente sua conduta no mundo exterior. $\mathrm{O}$ processo contratransferencial também não é usado como instrumento terapêutico pelas mesmas razões.

A regressão e o processo de transferência na psicoterapia longa provocam a reemergência de muitos objetos internos do paciente que, ao longo do tempo, levam-no a modificar suas estruturas patológicas.

Quanto à elaboração ou "insight", pode-se dizer que consiste em um desligamento progressivo junto ao terapeuta. Os elementos que compõem essa elaboração são o tempo, a projeção, a introjeção e o manejo com outros mecanismos de defesa. Esses elementos não são obrigatoriamente manejados na psicoterapia de tempo limitado.

Depois de um ano que o terapeuta residente permanece cuidando do paciente, o vínculo estabelecido fica interrompido pelo fator tempo. Portanto, o enfoque fica restrito à elaboração em um nível fundamentalmente cognitivo. Na psicoterapia de tempo limitado, não existe a história revivida de um processo paciente-terapeuta, de maneira mais profunda, mas, sim, superficial. Isto pode ser útil para que a criança se adapte à realidade de um modo mais saudável.

O importante é ajudar a criança a tomar consciência do papel que pode desempenhar na direção de sua própria vida, ampliando e amadurecendo seu ego pequeno e imaturo, através da "técnica de espelho" e amplificação de símbolos. Ajudar o paciente a perceber que ele tem capacidade de resolver seus próprios problemas, esperando que ele tenha introspecção, que é o pré-requisito para a terapia bem sucedida através das experiências, atitudes, pensamentos e sentimentos que vai tendo no processo terapêutico.

O terapeuta sabe que há necessidades dentro de cada ser humano e que o organismo está lutando constantemente para satisfazê-las e ele deve saber criar oportunidades para que essa luta se processe positivamente.
A criança, devido ao estado de frustração emocional em que se encontra, sente-se feliz de poder dispor, durante duas sessões por semana, de uma pessoa adulta que lhe dá atenção, que a escuta, que a compreende realmente, dentro de uma atmosfera de segurança e liberdade que, até então, pouco havia experimentado $^{(7)}$.

Com isso, supõe-se que ocorra a eliminação da sintomatologia, levando a criança a se adaptar às exigências do meio ambiente, da família e da escola. Espera-se que ela adquira um processo individual de maturação. É uma abordagem útil, ainda que pouco definida e que merece estudos mais abrangentes, assim como as psicoterapias profundas, que também não oferecem uma formação teórico-clínica consistente ${ }^{(9)}$.

Na psicoterapia longa com crianças, consideram-se as relações transferenciais e contratransferenciais. Nessa relação, procura-se entender o máximo possível cada paciente. Durante as sessões, a relação terapeuta e criança é necessariamente interpretada e vivenciada, procurando-se prestar atenção às sutilezas psicológicas envolvidas no encontro terapêutico. Exige um maior número de sessões semanais, duas, três ou mais para os casos mais graves, durante três anos ou mais. Em nossa experiência pessoal, observamos que duas sessões semanais são suficientes.

Os vínculos emocionais que surgem entre paciente e terapeuta e vice-versa são importantes no processo de transformação da criança. Além dessa relação, outro fator decisivo na psicoterapia profunda é a relação consciente-inconsciente ${ }^{(3)}$. A consciência é capaz de perceber acontecimentos internos e externos e o nosso trabalho é interpretá-los. Quando a consciência da criança está confusa, em desordem, devido a uma situação de vida, procura-se ajudá-la, levando-a a um processo de compreensão ou "insight" para que, desta forma, o processo de transformação possa ir ocorrendo, como também a uma amplificação do seu ego tornando-o mais organizado.

Esses aspectos vão se integrando na consciência e são de ajuda para o equilíbrio psíquico e o desenvolvimento da personalidade infantil. Assim, a consciência da criança vai crescendo sobre a base desse processo. A outra função do terapeuta é a de ajudar a criança a lidar com os estímulos internos, ou seja, os que vêm do inconsciente, e ajudar a lidar com os estímulos externos, que são aqueles que vêm do mundo exterior, no sentido de se desenvolver a maturação e 
adquirir capacidade de assimilar as experiências vividas. Desse modo, a criança vive melhor consigo mesma e perante a sociedade, pois os transtornos psicológicos e o desenvolvimento da criança não se acham determinados unicamente pelo ambiente, mas, também, pela própria criança.

Como nas demais técnicas psicoterapêuticas, na psicoterapia longa, a criança expressa suas idéias, suas emoções e afetos, muitos dos quais são inconscientes para ela, e é função do terapeuta fazer com que a mesma os perceba. Por exemplo, muitos pacientes não se percebem hipercinéticos, ou mesmo agressivos, e essas alterações devem ser integradas no ego, e eles devem se perceber hipercinéticos ou agressivos.

Acrescentamos, ainda, que há uma junção entre a sugestão e o método psicoterápico descrito, ou seja, a técnica de interpretação; principalmente quando é dissecada em todas as suas formas possíveis, a sugestão está embutida. A sugestão também ocorre em junção à técnica da amplificação dos símbolos. Esta também tem seu valor terapêutico, pois se manifesta e age na relação. Acreditamos que ela sempre está associada no poder da palavra, não a negamos e nem mesmo a ignoramos, ficamos atentos a ela e em relação a seus benefícios terapêuticos ${ }^{(9)}$. Pode ser mesmo um fator terapêutico mágico, contudo, de ajuda.

A essência da psicoterapia de tempo limitado e longa é a comunicação e exploração das convicções e dos estados subjetivos do paciente ${ }^{(10)}$. É uma tarefa difícil, sobretudo quando aplicada à criança que, geralmente, não traz para a relação terapêutica os sintomas, sinais e outros aspectos como veículos de comunicação.

O livre brincar e desenhar, incluindo os jogos, substituem, muitas vezes, e ou complementam as verbalizações, uma vez que esses são os meios naturais de expressão na criança. A atividade lúdica está intimamente ligada à tendência de comunicar-se através da expressão corporal e da atividade motora.

A brincadeira desempenha um papel significativo para a criança, no teste de realidade e na expansão de seu domínio. É também uma forma de comunicação. O terapeuta fala com ela através de jogos. O padrão do jogo dramatiza a experiência emocional da criança, seus conflitos, suas culpas e medo e, assim, reflete a brecha entre o que é real e o que é fantasia na mente da mesma ${ }^{(11)}$.

\section{ORIENTAÇÃO FAMILIAR}

Quando a criança é trazida para um atendimento psiquiátrico com um determinado sintoma, vem acompanhada por uma família que também merece uma atenção especial pois, muitas vezes, o problema da criança é indicador de que algo não vai bem com este grupo familiar e não só especificamente com ela, cujo problema é o que emerge, o que incomoda. Se nossa abordagem visar apenas às queixas da criança, o trabalho ficará seriamente comprometido.

É preciso discriminar o que se passa na família, quais as condições emocionais desses pais, se o sintoma da criança é realmente um obstáculo a seu desenvolvimento ou se, ao contrário, é um grito de socorro, pedindo mudanças no modo de lidar com ela e com seu mundo mental.

Estaríamos fazendo um trabalho pouco eficaz, se não promovêssemos um verdadeiro compromisso entre a criança, sua família e o terapeuta. As chances de sucesso do atendimento ficariam prejudicadas ${ }^{(12)}$, visto que o êxito do tratamento depende tanto do vínculo de confiança estabelecido entre a criança, seus pais e o terapeuta, como também da disponibilidade familiar em modificar os elementos patogênicos de caráter pessoal e ambiental $^{(11)}$.

A orientação familiar é um processo útil no tratamento dos pacientes. Em essência, procura-se entender quais são os fatores psicossociais que se relacionam com a psicopatologia da criança, e concentram-se esforços no sentido de alterar esses fatores, com o intuito de aliviar a sintomatologia do paciente.

A criança, na maioria das vezes, é membro de uma família que poderá acompanhá-la no momento do adoecer. Poderá ser solicitado ao médico parecer sobre diagnóstico, prognóstico e tratamento sobre o familiar doente.

É um trabalho que requer do médico muita habilidade, pois os familiares poderão reagir de diferentes maneiras frente ao fato de estarem sendo informados à respeito da doença, do tipo de cuidado e tratamento que a criança necessita, assim como das características evolutivas do quadro clínico ${ }^{(10)}$.

Os familiares poderão sentir-se culpados e inconscientemente projetar sua culpa no médico, criticando-o de diferentes formas. Outras vezes, projetam sobre a criança suas próprias necessidades. Desta forma, a criança não recebe por parte deles cuidados próprios de sua idade, além da exigência de possuí- 
rem atitudes próprias de adultos. Por exemplo, certas atitudes paternas que projetam os seus valores ou ideais não realizados em seus filhos, exigindo que os mesmos cursem determinadas escolas, estudem línguas estrangeiras, pratiquem determinados tipos de esporte e estudem música. Tudo isso traduzindo um nível de exigência elevado e ilimitado.

Por outro lado, outros tipos de pais apresentam características opostas das exemplificadas acima, ou seja, nada exigem e cobram dos filhos. Procuram realizar todos os desejos possíveis dos mesmos e acabam não criando condições para que eles desenvolvam suas potencialidades e não os permitem sofrerem frustrações, que é uma outra forma de não impor limites. Ignora-se a necessidade de ajudá-los a reconhecer os limites que a realidade impõe. A criança pode ficar assim sem noções de limites e, portanto, com dificuldades escolares, falta de asseio corporal, expor-se a situações de perigo, de rivalidades intensas e competições invejosas com irmãos e colegas, entre outras manifestações. A imposição de limites é o recurso através do qual se fornecem esses ensinamentos.

Outras famílias superprotegem a criança, podendo torná-la muito dependente. Outros familiares utilizam-se da negação, que não os permite reconhecer as limitações do paciente, como, por exemplo, as crianças com dificuldades de fala, como a gagueira, que acabam intensificando o quadro psicopatológico, agravando-o e diminuindo a sua auto-estima pela tentativa de correção da gagueira.

O médico, nesses casos, deve atuar no sentido de fazer com que os familiares aceitem o doente sem ressentimentos, culpas, negação e superproteção. Devem aprender com o médico o manejo desses sentimentos e comportamentos para tratar do seu familiar doente de forma adequada e realista ${ }^{(13)}$.

Os pais devem ser esclarecidos quanto à origem da dificuldade da criança, sua evolução e a maneira de lidar com o problema. Eles devem sempre saber a verdade. Necessitam ser informados e entenderem que suas atitudes influenciam no distúrbio emocional da criança. Assim, por exemplo, no caso de pacientes epilépticos, os pais se assustam com a crise e as reações colaterais. Esclarecimentos aos pais devem ser dados no sentido de reduzir a ansiedade e evitar que se sintam culpados, explicando a natureza da doença.

A culpa é uma reação quase sempre presente entre pais de crianças doentes.
Em muitos distúrbios emocionais, especialmente os mais severos, como alterações orgânico-cerebrais e esquizofrenias, os pais acusam-se entre si. Uma parte essencial da discussão com os pais é orientá-los para que não censurem ou se culpem e mostrar-lhes que a situação se agrava se eles não se compreenderem mutuamente. Mesmo quando o problema comportamental da criança é devido à conduta inadequada dos pais, é imprudente entrar diretamente na questão. O importante é o ajustamento das tensões familiares, procurando transformar os conflitos destrutivos em construtivos.

Em relação à culpa parental, ela só deve ser diluída se doentia, e portanto, nunca totalmente eliminada. Há nela uma característica normal e até necessária à saúde mental. É uma emoção construtiva e positiva, pois ela é a percepção do certo e do errado, do que se deve ou não se deve ser. É normal a culpa surgir quando há discrepância entre o que se é e o que se deve ser, ou o que se faz e o que se deve fazer. A culpa é inerente à condição humana. Cada ser humano traz em si sua constituição específica de vida, uma constituição interminável que pode ser substituída por outra. O exemplo disso é a culpa que tem uma base inata.

Sabe-se que a fobia escolar tem, em sua gênese, a relação mãe e filho. A superproteção materna leva a criança a uma situação de dependência e essa dependência cria uma hostilidade infantil contra a mãe. Nesses casos, a psicoterapia da mãe quase sempre é indicada.

É importante descobrir a origem da ansiedade dos pais e, para tanto, devem ser analisadas as relações do casal entre todos os integrantes do grupo em que vivem, o modo que reagem ante as influências do meio, as características físicas e psíquicas. Orientar os pais no sentido de diminuir as tensões ambientais, reduzindo as atitudes agressivas e ajudá-los a entender que o seu comportamento ansioso pode contagiar os filhos, sendo, então, necessário o controle da ansiedade para beneficiar o tratamento dos mesmos.

É freqüente que, na entrevista inicial, as queixas apresentadas pelos pais não sejam as reais. Eles hesitam em descrevê-las devido às suas ansiedades. Portanto, breves orientações com os pais são importantes para que eles se sintam confiantes no sentido de informar sobre a natureza do distúrbio comportamental do filho, para tranqüilizá-los de seus sentimentos de culpa e dar sugestões no sentido de ajudar o filho $^{(10)}$. 
Um fato importante que observamos atualmente é o hábito indiscriminado de expor as crianças durante horas diante da televisão. Esta modalidade cerceia a criança da possibilidade de exercícios físicos para seu desenvolvimento mental e motor. São impedidas de expandir suas fantasias e do exercício saudável da atividade lúdica. Os problemas decorrentes da assistência precoce e abusiva à televisão é fator importante a discutir no processo de orientação dos pais, sobretudo, no sentido de impor limites.

A ausência de limites também pode ser observada nas escolas onde as exigências são poucas, os métodos de ensino simplificados, permitindo o uso da calculadora em lugar de cálculos mentais, sem uma exigência maior no aperfeiçoamento da leitura e escrita e muita tolerância na questão da disciplina. Verificamos, também, que os pais evitam estabelecer contatos com as escolas ficando, desse modo, pouco informados em relação ao rendimento e comportamento escolar dos filhos ${ }^{(14)}$.

A empatia é a compreensão que o médico tem dos sentimentos, desejos e conflitos associados aos sinais e sintomas tanto do paciente como das reações dos familiares, porém sem o seu envolvimento emocional. Pela empatia o médico coloca-se no lugar do paciente e de sua família, procurando ter uma compreensão de seus sofrimentos, de suas angústias e dúvidas, sem, no entanto, confundir-se com eles ${ }^{(15)}$. Isso é importante na relação médico e paciente, porque é nessa situação que ocorre o entendimento. $\mathrm{O}$ objetivo é compreender a criança e a família, influenciando, em todo o tratamento, o máximo possível, como o maior desejo de ajuda. O entendimento chega a romper até mesmo barreiras como a competição invejosa e ciúme, muito comum entre irmãos. O psiquiatra in- fantil deve influenciar nessas situações e isso aparece como resultado da empatia.

A orientação coloca o psiquiatra da infância diante de deveres éticos importantes. Ele deve ter como características de personalidade grande sensibilidade, ser paciencioso, tranqüilo e espontâneo. Sem essas características, a relação com o paciente e a família pode ficar prejudicada e dificultar uma compreensão mais profunda entre esses, o que acaba prejudicando mudanças desejadas e construtivas.

Além dessas características, o psiquiatra infantil necessita de um treinamento no sentido de não projetar seus próprios conflitos no paciente e família. Portanto, ele deve ter uma boa compreensão de si mesmo. Isto é importante para ter uma conduta objetiva e sem preconceitos, julgamentos ou condenações, que podem levar a repressões, e reprimir é incorreto. Os problemas, na orientação, não devem ser abordados como questões de moralidade, mas, sim, de saúde mental.

A terapia familiar é indicada à medida em que é diagnosticada a psicopatologia nos pais ou responsáveis. A prática da terapia familiar é realizada pelos médicos residentes em psiquiatria, sempre com supervisão do docente.

O tratamento psiquiátrico infantil envolve os pais ou responsáveis. A família não pode mais ser apenas um "pano de fundo" no contexto terapêutico. É importante orientá-la como um sistema unitário, valorizando-se os vínculos afetivos. As relações familiares devem ser avaliadas para que mudanças possam ser efetuadas e resultados terapêuticos significativos possam ocorrer entre pai, mãe, filho e irmãos. Os sintomas do sistema familiar também devem ser avaliados e isso contribui efetivamente no contexto diagnóstico da psicopatologia infantil e seu tratamento ${ }^{(16)}$.

GOLFETO JH \& MIAN H. Psychotherapeutic approach to children and family of the University of São Paulo - Ribeirão Preto General Hospital. Medicina, Ribeirão Preto, 32: 203-210, apr./june 1999.

ABSTRACT: Psychotherapy is one of the treatments used concerning Children Psychiatry as well as family orientation and psychopharmacotherapy. It can be given different classifications according to theoretical basis, target of intervention, and therapy objectives or duration. We intend to report the psychotherapeutic approach called short-term psycotherapy, which we have adopted in the Psychiatric Clinic for Children of the University of São Paulo - Ribeirão Preto General Hospital, and to compare them with other ones used in long-term psychotherapy. We also report our experience with family orientation. The patients are previously evaluated and after clinical discussion they are assigned to the procedures which can be developed alone or along with other ones.

UNITERMS: Child Psychiatry. Psychotherapy. Child. Family. Orientation. 


\section{REFERÊNCIAS BIBLIOGRÁFICAS}

1 - UCHÔA DM. Princípios gerais de psicoterapia na infância. In: KRYNSKI S. Temas de psiquiatria infantil. Guanabara Koogan, Rio de Janeiro, p. 300-306, 1977.

2 - DULCAN MK. Tratamento de crianças e adolescentes. In: TALBOTT JA; HALES RE \& YUDOFSKY SC, eds. Tratado de psiquiatria. Artes Médicas, Porto Alegre, p. 733-758, 1992.

3 - GOLFETO JH. Psicoterapia infantil: uma abordagem Junguiana. Arq Bras Psiquiatr 41: 79-84, 1989.

4 - KALFF DM. Sand play: a psychotherapeutic approach to the psych. Lindsay Smith, Boston, p. 62-78, 1980.

5 - ROGERS CR. 0 tratamento clínico da criança problema. Martins Fontes Editora, São Paulo, p. 165-241, 1979.

6 - WINNICOTT DW. O brincar: Uma exposição teórica. In: WINNICOTT DW. O brincar e a realidade. Editora Imago, Rio de Janeiro, p. 59-77, 1975.

7 - AXLINE VM. Dinâmica interior da criança - Ludoterapia. Interlivros, Belo Horizonte, p. 22-143, 1984.

8 - SMIRNOFF V. Psicanálise da criança. Editora Vozes, Petrópolis, p. 246-270, 1972.

9 - TAFURI MI. Tratamento psicanalítico de crianças. In: ASSUMPÇÃO Jr FB. Psiquiatria da infância e da adolescência. Editora Santos, São Paulo, p. 525-532, 1994.
10 - LEWIS M. Psicoterapia psicodinâmica individual intensiva: o relacionamento terapêutico e a técnica da interpetação. In: LEWIS M. Tratado de psiquiatria da infância e adolescência. Artes Médicas, Porto Alegre, p. 808-816, 1995.

11 - ACKERMAN NW. Diagnóstico e tratamento das relações familiares. Artes Médicas, Porto Alegre, 1986.

12 - LISONDO ABD et al. Psicanálise de crianças: um terreno minado? Rev Bras Psicanal 30: 9-26,1996.

13 - GOLFETO JH. A psicossomática de um caso clínico infantil. Rev ABP-APAL 13: 68-74, 1991.

14 - SOIFER R. Psicopatologia dos transtornos da conduta. In: SOIFER R. Psiquiatria infantil operativa. Artes Médicas, Porto Alegre, p. 296-299,1992.

15 - GOLFETO JH \& MIAN H. Aspectos psicológicos da relação médico-paciente. In: ZUARDI AW et al, orgs - Estudos em saúde mental - 1998. Comissão de Pós-Graduação em Saúde Mental, Faculdade de Medicina de Ribeirão Preto da Universidade de São Paulo p. 214-242, 1998.

16 - KERNDERG PS. Psicoterapia individual. In: KAPLAN HI \& SADOCK BJ eds. Tratado de psiquiatria, 6 ${ }^{a}$ ed, Artes Médicas, Porto Alegre, p. 2602-2616, 1998.

Recebido para publicação em 30/07/98

Aprovado para publicação em 01/06/99 